\title{
Unemployment, discouraged workers and female labour supply
}

\author{
Richard BlundelL*, John Ham $\dagger$ And Costas MeghiR* \\ *Department of Economics and Institute for Fiscal Studies, \\ University College London, Gower Street, London, WC1E 6BT \\ $\dagger$ Department of Economics, Forbes Quadrangle, University of \\ Pittsburgh, Pittsburgh, Pennsylvania 15260, U.S.A.
}

Received 11 September 1997, accepted 10 November 1997

\begin{abstract}
Summary
We develop and implement a model of female participation, labour supply and employment that incorporates both search unemployment and discouraged workers. We show that in an intertemporal environment with fixed costs, search costs, permanent lay-offs and infrequent job arrivals, an adaptation of the standard (two-stage budgeting) approach to modelling hours for the employed remains appropriate. Moreover, this model indicates a clear-cut role for business-cycle variables in a participation equation that controls for expected market wages. Our empirical results indicate that businesscycle variables do indeed play a statistically significant role in such an equation. Our approach also provides a straightforward means of calculating the separate effect of fixed costs and search costs on the participation decision.

(C) 1998 Academic Press Limited
\end{abstract}

J.E.L. Classification: J22, J64, D91.

Keywords: Labour supply, cross-section data, limited dependent variables, unemployment, search models, discouraged workers.

\section{Introduction}

In this paper we consider two important features of empirical labour supply behaviour. First, business-cycle variables have been found to play an important role in reduced-form equations for both wage and probit employment functions on micro-economic data. Second, micro-data sources indicate that a significant number of individuals who do not work are actively seeking employment in a given week. The aim of our paper is to use a search theoretic 
framework to develop an empirical model of employment, search and labour supply that explicitly provides a role for business-cycle variables in participation decisions and allows for job seekers. Within this framework we also provide a mechanism for determining the importance of search costs and fixed costs of work in participation decisions.

Conceptually, there are three reasons why business-cycle variables should affect observed participation (but not necessarily labour supply). First, such variables will enter through the mean of the wage offer distribution (if one does not condition on it) since participation decisions involve comparing reservation wages to market opportunities. Second, conditional on the characteristics of the wage offer distribution, participation will be higher when demand conditions are good and hence individuals anticipate that it will be easier to obtain a job. Finally, given labour force participation, one is likely to find a job faster when employment conditions are good. If we do not distinguish the participation decision from the conditional employment probability and simply estimate a work/non-work probability, this will be a third avenue for demand-side variables to enter the equation.

The discouraged worker concept has a long history in labour economics. For example, Ehrenberg and Smith (1988) include the following discussion: "Noting the substitution effect that accompanies a falling expected wage, some have argued that people who would otherwise have entered the labour force become 'discouraged' in a recession and tend to remain out of the labour market. Looking for work has such a low expected pay-off for them that such people decide that spending time at home is more productive than spending time in job search. The reduction of the labour force associated with discouraged workers in a recession is a force working against the 'added-worker' effect-just as the substitution effect works against the income effect." Our aim in this paper is to place this concept in a formal theoretical and empirical setting.

The point of departure for our work is the model of Burdett and Mortensen (1978). First, we show that intertemporal twostage budgeting $\dagger$ can be used even in the presence of job search to identify the parameters of the within-period utility function by conditioning on consumption. Second, we show how we can use sample separation information, which splits the non-workers into job seekers and non-seekers, to identify a labour force participation probability and a conditional employment probability. A major difference between our work and previous empirical research that has acknowledged this split, such as

$\dagger$ See Altonji (1982), MaCurdy (1983) and Blundell and Walker (1986) for a description of the implications of two-stage budgeting for life-cycle labour supply. 
Flinn and Heckman (1983) and Burdett et al. (1984), is our incorporation of labour supply and the subsequent identification of discouraged workers. $\dagger$ The development of a labour supply model in the presence of search costs leads naturally to a discussion of discouraged workers. A precise definition is given in the case of a degenerate wage offer distribution and it is found to extend naturally to a well-identified concept provided the wage offer distribution is bounded above.

Our data come from the U.K. Family Expenditure Survey over the period 1981-1984. During this period unemployment in Britain averaged over 12\%. Particularly for an economy going through such an extreme business cycle, it does not seem sensible to simply assume away, a priori, unemployed workers and discouraged workers. $\$$ Moreover, since we classify job seekers as labour market participants, our participation equation is consistent with the standard definition of participation used in calculating official labour force statistics, as opposed to the now standard fixed-cost model of Cogan (1981), which confounds participation behaviour with the probability of finding a job within a particular period.

Our model provides a clear-cut role for business-cycle variables, and in our empirical work we find that such variables are economically important and statistically significant in both the job availability index and the labour force participation decision (conditional on the expected market wage). Since such demand variables have no role in the fixed-cost model of Cogan (again conditional on the wage), our results provide an implicit rejection of this model.§ Including business-cycle variables significantly reduces the role of time dummies in participation. Finally, our approach provides a means of calculating the separate effect of fixed costs of work and search costs on the participation decision. To the best of our knowledge, no such calculation has appeared in the literature. II

The remaining sections of the paper are as follows. In Section 2 , a life-cycle labour supply framework is developed that acknowledges search and unemployment. Section 3 presents our

$\dagger$ It should be noted that these studies focus on transitions between labour market states, while our data do not allow us to do this.

\$ For evidence on the importance of accounting for unemployment in the labour supply analysis of men, see Ashenfelter (1980) and Ham (1982, 1986a,b).

$\S$ Note that while demand variables do belong in the reduced-form probit equation of Cogan's model (since they enter through the wage equation), they generally are not included in this equation, although Nakamura and Nakamura (1981) and Mroz (1987) do include unemployment rates in the reduced-form participation equation. These demand variables offer an additional source of identification in the model.

II Cogan (1981) provides an estimate of fixed costs of work. 
statistical model and Section 4 provides the empirical results. Some conclusions are drawn in Section 5.

\section{Participation, search and labour supply in a model with search costs and unemployment}

In this section we investigate two issues involving the relationship between search theory and the specification of empirical labour supply models. The first issue relates to the extent to which a theoretical search model can provide a useful categorization of behaviour corresponding to the split in our data between those women who are searching and those women who are non-participants (neither in work nor searching). Second, we examine whether standard life-cycle consistent labour supply models can be useful in representing the hours of work decisions for employed women in a model with job seekers. We begin by considering a model that is similar to that analysed by Burdett and Mortensen (1978). An individual chooses to participate in the labour market if the expected benefits from seeking employment outweigh the costs of search. We assume that there are no temporary lay-offs and that there is no on-the-job search. We also begin by assuming that individuals face a degenerate wage offer distribution and that there is a constant search intensity.

Individuals are found in one of the following labour market states: (i) non-participation; (ii) search; and (iii) employment. Individuals in non-participation receive job offers at a rate of $\alpha_{o}$ per period. (This may well be zero as in Burdett and Mortensen.) Individuals who search incur time costs of $s$ per period and money costs of $c$ per period and they receive job offers at a rate of $\alpha_{s}$ per period, $1>\alpha_{s}>\alpha_{o}$. An individual who finds a job in period $t$ has the option of employment in period $t+1$ at the real hourly wage $w_{t+1}$. (Note that $w_{t+1}$ is a random variable in period $t$.) Individuals in employment pay fixed time costs $\tau$ and monetary costs $f$ and face a net lay-off rate of $\delta$. If they are employed in $t+1$ they receive $w_{t+1}$. Individuals are assumed to be infinitely lived (see, for example, Burdett and Mortensen, 1978, for a discussion of this assumption) and maximize lifetime utility subject to a lifetime budget constraint.

Consider first the value function associated with non-participation in period $t, V_{t}^{0}$. In non-participation, an individual achieves current-period utility level $U\left(T, C_{t} ; \boldsymbol{z}_{t}\right)$, where $T$ is the maximum leisure time available, $C_{t}$ is the level of real consumption and $\boldsymbol{z}_{t}$ a vector of taste shift characteristics. However, the total value $V_{t}^{o}$ of non-participation depends on expected future outcomes, conditional on current non-participation. Even though the individual chooses not to search, she may wish to work in the future 
at wage $w_{t+1} \cdot \dagger$ For non-participants there is a job arrival rate at the end of period $t$ of $\alpha_{o}$. If a job offer is received, at the beginning of the next period the individual will choose between employment at a wage $w_{t+1}$ (unknown in $t$ ), search and non-participation. If she does not receive an offer, she chooses between search and nonparticipation at the next period. As a result, the total value function of non-participation in period $t$ takes the following form:

$$
\begin{aligned}
V_{t}^{o}= & \max \left\{U\left(T, C_{t} ; z_{t}\right)+\varphi E_{t}\left(\alpha_{o} \max \left[V_{t+1}^{o}, V_{t+1}^{s}, V_{t+1}^{e}\right]\right.\right. \\
& \left.\left.+\left(1-\alpha_{o}\right) \max \left[V_{t+1}^{o}, V_{t+1}^{s}\right]\right)\right\},
\end{aligned}
$$

where $\varphi$ is a personal discount factor and $V_{t+1}^{o}, V_{t+1}^{s}$ and $V_{t+1}^{e}$ are the value functions associated with non-participation, search and employment in $t+1$ respectively.

Maximization of Equation (1) over $C_{t}$ and $A_{t}$ takes place subject to the asset accumulation constraint

$$
C_{t}=\left(1+r_{t}\right) A_{t-1}-A_{t}+y_{t}
$$

where $A_{t}$ is the level of end-of-period- $t$ assets, $r_{t}$ is the real return on assets held at the level of period $t-1$ and $y_{t}$ is the level of other income in period $t$. Conditional expectations in Equation (1) are defined such that $E_{t}(.) \equiv E\left(. \mid \Omega_{t}\right)$, where $\Omega_{t}$ is the information set in $t$.

Corresponding to Equation (1) there is a value function associated with search. The current period cost of search is measured in terms of both time costs $s$ and real consumption costs $c$. Given an arrival rate of $\alpha_{s}$ for job offers of those individuals incurring search costs, the value function for search takes the form

$$
\begin{aligned}
V_{t}^{s}= & \max \left\{U\left(T-s, C_{t}-c ; z_{t}\right)\right. \\
& +\varphi E_{t}\left(\alpha_{s} \max \left[V_{t+1}^{o}, V_{t+1}^{s}, V_{t+1}^{e}\right]\right. \\
& \left.\left.+\left(1-\alpha_{s}\right) \max \left[V_{t+1}^{o}, V_{t+1}^{s}\right]\right)\right\},
\end{aligned}
$$

with budget constraint Equation (2).

Finally, the value function for employment depends on the (net) lay-off rate $\delta$ and is given by

$$
\begin{aligned}
V_{t}^{e}= & \max \left\{U\left(T-h_{t}-\tau, C_{t}-f ; z_{t}\right)\right. \\
& +\varphi E_{t}\left((1-\delta) \max \left[V_{t+1}^{o}, V_{t+1}^{s}, V_{t+1}^{e}\right]\right.
\end{aligned}
$$

$\dagger$ Note that such an individual may wish to work at the current wage, but does not search because the costs outweigh the expected benefits. We describe such an individual as a discouraged worker. Alternatively, she may not wish to work in this period but may want to work in the future if her circumstances change or if $w_{t+1}>w_{t}$. 


$$
\left.\left.+\delta \max \left[V_{t+1}^{o}, V_{t+1}^{s}\right]\right)\right\}
$$

where $h_{t}$ is the hours of work supplied in period $t$. The budget constraint associated with Equation (4) is given by

$$
C_{t}=w_{t} h_{t}+\left(1+r_{t}\right) A_{t-1}-A_{t}+y_{t} .
$$

Now the information set in $t$ can be seen to contain all variables available in $t$ that are useful in predicting future real wages, future real interest rates, real other income and future demographic variables.

The model defined by Equations (1)-(5) implies a very useful result for empirical modelling: conditional on an individual being in employment, her marginal choice between hours and consumption $\left(h_{t}\right.$ and $\left.C_{t}\right)$ can only affect the second term in Equation (4) through $A_{t}$. As a result, her conditional hours of work can be modelled using a standard intertemporal two-stage budgeting approach equivalent to the $\lambda$-constant model of Heckman and MaCurdy (1980). To see this, rewrite Equation (5) as

$$
C_{t}=w_{t} h_{t}+\mu_{t},
$$

where $\mu_{t}=r_{t} A_{t-1}-\Delta A_{t}+y_{t}-f$ is a net dis-saving measure. For an individual in employment, maximization of Equation (4) subject to Equation (6) yields the marginal rate of substitution between hours and consumption, $-U_{h} / U_{c}=w$. Combining this condition with the budget identity (Equation (6)) yields a standard intertemporal labour supply equation. $\dagger$ For empirical purposes, we write this as $\$$

$$
h_{t}^{*}=g\left(w_{t}, \mu_{t} ; z_{t}, \beta\right)+u_{t},
$$

where $h_{t}^{*}$ is a latent hours of work variable and $\beta$ represents unknown preference parameters. In Equation (7) $u_{t}$ is an individual-specific error term whose properties are described below. In estimation we allow $\mu_{t}$ and $w_{t}$ to be endogenous. Of course, those observed in work will not be randomly selected; instead the individual's labour market state will be determined by the operations of the model (Equations (1)-(5)).

The usefulness of Equation (7) is clear. Hours of work decisions for workers depend on the current wage and an appropriately

$\dagger$ Blundell (1986) describes the equivalence between $\mu$-conditional and $\lambda$ constant approaches and provides an application of two-stage budgeting in a standard life-cycle problem.

$\ddagger$ Note that given data on consumption expenditure, Equation (6) can be used to solve for $\mu$. 
defined other income measure $\mu_{t}$ that summarizes all future expectations contained in the conditional expectation of the second term in Equation (4). Given $w_{t}$ and $\mu_{t}$ (and demographic variables $z_{t}$ ), hours of work for those employed do not depend on the wage offer distribution, lay-off and arrival rates or any other aspect of uncertainty.

The simplicity due to the two-stage budgeting approach is no longer helpful when we consider marginal conditions across any of the states described by Equations (1), (3) and (4). The conditions for two-stage budgeting do not prevail in general since any pairwise comparison of the second terms in each of the three value functions indicates that labour market participation and search have an effect on the future that is above and beyond their effect through $A_{t}$.

It is interesting to note how the standard fixed-cost model relates to the theoretical model defined by Equations (1)-(5). The fixedcost model imposes the constraint (i) $\alpha_{o}=\alpha_{s}=(1-\delta)=1$ or, alternatively, the constraint (ii) $\alpha_{s}=(1-\delta)=1$ and zero search costs. If one of these restrictions holds, there is no useful distinction between search and non-participation, and anyone who wants a job will find one. However, if neither of these restrictions holds, a Cogan-type approach will be inappropriate for a world defined by Equations (1)-(5).

Although we do not propose to estimate the full structural model based on Equations (1)-(5), this formulation does imply that a structural life-cycle labour supply function (for those in employment) provides a representation for hours of work that is consistent with this optimization problem. Moreover, it suggests that the participation equation, defined over the non-participants/ searchers/workers split, will depend on business-cycle factors that are conditional on the wage and other income variables. $\dagger$ As mentioned above, our participation rule groups searchers and workers together. The split between search and work can then be used to estimate a conditional employment equation (i.e. a process that determines work conditional on participation).

\section{An empirical representation}

\subsection{A STOCHASTIC FRAMEWORK}

In writing a sample likelihood function to estimate our model we must describe both an individual's labour market state and her

\footnotetext{
$\dagger$ In Appendix A we provide a simplified version of Equations (1)-(5) to increase the reader's intuitive understanding of the model. The role of business-cycle variables in the participation decision becomes transparent in this simplified model. We also allow for a non-degenerate wage offer distribution and endogenous search intensity in this simple model.
} 
desired hours of work conditional on being in employment. We have shown that a standard intertemporal supply function is consistent with the optimization problem (Equations (1)-(5)). Desired hours will therefore be described by an equation in the form of Equation (7).

To describe an individual's labour market state we need an index equation which defines her participation decision, and an index equation to define the probability that an individual would have a job available to her should she decide to participate. For the former we use a participation index $I_{i}$ for individual $i$ which is positive if participation is chosen, and which we shall write as

$$
I_{i}=\boldsymbol{x}_{\boldsymbol{i}}^{\prime} \gamma+\zeta_{i}
$$

where we have dropped the subscript $t$ for expositional purposes, $\zeta_{i}$ represents an additive stochastic term unobservable to the econometrician and $\boldsymbol{x}_{\boldsymbol{i}}$ is an observable vector which contains both labour supply variables (including the expected wage) and demand variables which enter directly through the lay-off and arrival rates (and possibly indirectly through the reservation wage and search intensity). We assume that a job will be available to the individual if the index function

$$
E_{i}=\omega_{i}^{\prime} \theta+v_{i}
$$

is positive, where $\omega_{i}$ is a vector containing demographic, economic and demand variables and $v_{i}$ is an error term representing unobserved differences across individuals. $\dagger$

We are now in a position to consider the appropriate contribution to the likelihood for the three groups of workers observed in our data: (i) the employed; (ii) the unemployed seeking work; and (iii) the non-participants. For an individual who is employed the likelihood contribution is

$$
L_{i}^{e}=f\left(h_{i}^{*} \mid I_{i}>0, E_{i}>0\right) \times \operatorname{Pr}\left[E_{i}>0 \mid I_{i}>0\right] \times \operatorname{Pr}\left[I_{i}>0\right] .
$$

The first term in Equation (10) reflects her current desired hours of work. The second term reflects the fact that she is in employment conditional on participation. Below we argue that the unconditional

$\dagger$ It is worth noting that, in general, the probability defined by a positive index (Equation (9)) is not the job arrival rate. For example, in the modified Burdett-Mortensen model discussed above, the probability that a job would be available is the probability of being employed in $t-1$ times the net retention rate $(1-\delta)$ plus the probability that an individual searches in $t-1$ times the arrival rate $\alpha_{s}$ plus the probability that an individual does not search times the arrival rate $\alpha_{0}$. 
index $E_{i}$ is unidentified and thus in what follows we will define the conditional probability

$$
\operatorname{Pr}\left[E_{i}>0\right] \equiv \operatorname{Pr}\left[E_{i}>0 \mid I_{i}>0\right] .
$$

The final term in Equation (10) relates to her decision to participate in the labour market.

For an individual seeking employment, we know that she participates and that conditional on participation, she has not found employment $\left(E_{i}>0\right)$. Such an individual contributes

$$
L_{i}^{s}=\operatorname{Pr}\left[E_{i}<0\right] \operatorname{Pr}\left[I_{i}>0\right] .
$$

Moreover, the contribution for non-participants is simply $\operatorname{Pr}\left[I_{i}<0\right]$. Combining these terms for a random sample, our estimation approach consists of maximizing the following sample likelihood

$$
\begin{aligned}
L= & \prod_{i \in e} f\left(h_{i}^{*} \mid E_{i}>0, I_{i}>0\right) \times \operatorname{Pr}\left[E_{i}>0\right] \times \operatorname{Pr}\left[I_{i}>0\right] \\
& \prod_{i \in s} \operatorname{Pr}\left[I_{i}>0\right] \operatorname{Pr}\left[E_{i}<0\right] \prod_{i \in n} \operatorname{Pr}\left[I_{i}<0\right],
\end{aligned}
$$

where $e$ denotes employment, $s$ denotes search and $n$ denotes nonparticipation.

Before moving to our empirical results we first consider a specific form for desired hours. We then go on to formally consider identification of the model and the relationship of this model to the standard fixed-cost models found in the literature.

\subsection{THE SPECIFICATION OF LABOUR SUPPLY FOR MARRIED WOMEN}

For any individual $i$, we specify desired hours of work as

$$
h_{i}^{*}=\alpha_{0}\left(z_{i}\right)-\beta\left(z_{i}, w_{i}\right)\left(\mu_{i}+a\left(w_{i}, z_{i}\right)\right) / w_{i}+u_{i},
$$

where $w_{i}$ is the real marginal after-tax wage rate and $\mu_{i}$ is other income constructed from the budget identity $(\mu=$ household consumption $-w h)$ as described in Section 2. $\dagger$ Furthermore, $\alpha_{0}\left(z_{i}\right)$, $\beta\left(z_{i}, w_{i}\right)$ and $a\left(w_{i}, z_{i}\right)$ are general functions of household-specific demographic and taste shift variables $z_{i}$. The precise form of

$\dagger$ Using the marginal after-tax wage to define $\mu$ is equivalent to linearizing the net-of-tax budget constraint. 
these is left as an empirical choice but it should be noted that Equation (14) nests the popular, although restrictive, Stone-Geary or LES specification (see Blundell and Meghir, 1986). The disturbance term $u_{i}$ is interpreted as an additive random preference effect attached to the income coefficient $\beta\left(z_{i}, w_{i}\right)$ so that its variance is proportional to $\left(\left(\mu_{i}+a\left(w_{i}, z_{i}\right)\right) / w_{i}\right)^{2}$.

In estimation, four age groups are defined for children $(0-2,3-4$, 5-10 and $11+$ ) and corresponding to these are the numbers $\mathrm{K} 1$, $\mathrm{K} 2, \mathrm{~K} 3$ and $\mathrm{K} 4$ of dependent children in the household in each category. Dummies are also defined by DK1 $=1$ (if $\mathrm{K} 1>0$ ), DK2 = 1 (if $\mathrm{K} 2>0, \mathrm{~K} 1=0$ ), $\mathrm{DK} 3=1$ if $(\mathrm{K} 3>0, \mathrm{~K} 1=\mathrm{K} 2=0)$ and $\mathrm{DK} 4=1$ if $(\mathrm{K} 4>0, \mathrm{~K} 1=\mathrm{K} 2=\mathrm{K} 3=0)$ to capture the effect of the age of the youngest child. (Note that the base case is a childless couple.) The form of the $\alpha_{0}\left(z_{i}\right)$ is given by

$$
\begin{aligned}
\alpha_{0}\left(z_{i}\right)= & \alpha_{00}+\alpha_{01} \mathrm{DK}_{i}+\alpha_{02} \mathrm{DK} 2_{i} \\
& +\alpha_{03} \mathrm{DK}_{i}+\alpha_{04} \mathrm{DK} 4_{i}+\alpha_{0 a} \mathrm{Age}_{i} .
\end{aligned}
$$

Thus, we assume that $\alpha_{0}\left(z_{i}\right)$ depends on the wife's age and the age of her youngest child. The form of the $a\left(w_{i}, z_{i}\right)$ is given by

$$
a\left(w_{i}, z_{i}\right)=w_{i} \alpha_{o}\left(z_{i}\right)-\alpha_{q}\left(z_{i}\right)
$$

where

$$
\alpha_{q}\left(z_{i}\right)=\alpha_{10}+\alpha_{11} \mathrm{~K} 1_{i}+\alpha_{12} \mathrm{~K} 2_{i}+\alpha_{13} \mathrm{~K} 3_{i}+\alpha_{14} \mathrm{~K} 4_{i} .
$$

Note that we assume that $\alpha_{q}\left(z_{i}\right)$ depends on the number of children in each age group.

The income coefficient $\beta\left(z_{i}, w_{i}\right)$ is given by

$$
\begin{aligned}
\beta\left(z_{i}, w_{i}\right)= & \beta_{0}+\beta_{1} \mathrm{DK} 1_{i}+\beta_{2} \mathrm{DK} 2_{i}+\beta_{3} \mathrm{DK} 3_{i} \\
& +\beta_{4} \mathrm{DK} 4_{i}+\beta_{w} \ln w_{i}+\beta_{a} \mathrm{Age}_{i}+\beta_{a a} \mathrm{Age}_{i}^{2} .
\end{aligned}
$$

Thus, we assume that the income coefficient depends on the wife's age, the age of her youngest child and her log wage. By including the wage term in $\beta()$, we break the restrictive additive separability between hours and consumption inherent in the LES. The model (Equation (14)) is therefore a reasonably flexible labour supply specification. It should be noted, for example, that a negative $\beta_{w}$ coefficient can generate a backward-bending labour supply curve. The traditional interpretation of $\alpha_{0}()$ and $\alpha_{q}()$ is that they are the maximum feasible hours of work and subsistence consumption, respectively. This interpretation is potentially misleading since $\alpha_{q}()$, the implied minimum consumption, can be negative while at 
the same time the model (Equation (14)) is consistent with economic theory.

\subsection{IDENTIFICATION}

In this section we discuss the assumptions that we must make to identify the relevant equations in our model: (i) the reduced-form participation equation; (ii) the participation equation conditional on the wage $w$ and other income $\mu$, subsequently referred to as the structural participation equation; (iii) the job availability index conditional on participation; and (iv) the structural hours equation (i.e. conditional on both the wage $w$ and other income $\mu$ ).

The reduced-form equation for participation is (non-parametrically) identified from the sample split between non-participants on the one hand and job seekers and workers on the other. The structural participation equation, which is including the wage and other income, is identified by assuming that terms in the husband's age and education (and their interactions with the wife's education) enter the marginal wage and income equations but do not enter the structural participation equation. Here we are exploiting the fact that the wife's marginal tax rate depends on the husband's earnings. We also assume that terms in the wife's education enter the marginal wage equation but not the structural participation equation. We control for selection bias in estimating the wage equation using a Heckman (1979) correction. The wage equation is identified by including the children variables in the probit equation and excluding these variables from the wage equation.

Consider next the identification of the job availability index. Ideally, we would like to estimate this index for a randomly chosen woman, i.e. an unconditional index. However, we only observe the employment outcome for those who participate in the labour force, and to estimate an unconditional employment equation, we need a variable that would enter the participation index but not the employment index function. One possibility is to argue that only demand-side variables enter the employment index, thus allowing us to exclude supply-side variables (e.g. children) or husband's characteristics from the employment equation. Unfortunately, these latter variables can affect the employment outcome through the choice of the reservation wage and search intensity. Thus, we conclude that valid exclusion restrictions between employment index and the participation index are unavailable and only a conditional index function for employment is identified.

Finally, we consider the structural labour supply equation. This equation is conditional on both participation $\left(I_{i}>0\right)$ and employment $\left(E_{i}>0\right)$. Moreover, it contains two endogenous variables: the marginal wage and other income. Thus, we essentially need at least 
four variables excluded from the hours equation, which enter the (reduced-form) participation index, employment index, wage equation and other income equation. First, we exclude terms in the wife's education. Second, we exclude age and education terms for her husband. Third, we exclude business-cycle variables: regional unemployment, regional vacancies, regional redundancies and female unemployment by age. $\dagger$

\subsection{SEARCH COSTS AND FIXED COSTS}

Since the likelihood (Equation (13)) bears some resemblance to those found in the fixed-cost literature (see, for example, Hausman, 1980; Cogan, 1980a, 1980b, 1981) and since Mroz (1987) has demonstrated the importance of relaxing the strict assumptions of the Tobit model, it is worthwhile discussing how our model differs from previous approaches. If we define $G_{i}>0$ as the joint event $\left(I_{i}>0\right.$, $E_{i}>0$ ), in the absence of sample separation information between seekers and non-participants we have, in place of Equation (13),

$$
L^{G}=\prod_{i \in e} f\left(h_{i}^{*}\right) \cdot \operatorname{Pr}\left[G_{i}>0 \mid h_{i}^{*}>0\right] \prod_{i \in o}\left(1-\operatorname{Pr}\left[G_{i}>0\right]\right),
$$

where $e$ denotes workers and $o$ denotes all non-workers. Equation (18) is the sample likelihood function for the standard two-equation fixed-cost model of female labour supply. In the absence of sample separation information, we are back in the standard model, and only the aggregate $G$ index is identified, while in our case we can identify $I_{i}$ separately from $E_{i}$.

Furthermore, in our model even if an individual satisfies $I_{i}>0$ and participates in the labour market, she will not be observed in employment unless she also finds a job (i.e. $E_{i}>0$ ). Also, the usual selectivity (fixed-cost) approach and the Tobit model misclassify job seekers as non-participants. Finally, conditional on an individual's market wage, in the fixed-cost model the $\operatorname{Pr}\left(I_{i}>0\right)$ depends only on labour supply variables and there is no additional role for demandside variables in this index. In a model with search costs and an employment probability of less than one, there is a clear-cut role for such variables. In fact, it is clear from Section 2 that our model is consistent with both fixed costs and search costs. Indeed, it is possible within the context of our model to assess the relative importance of fixed costs and search costs in participation decisions.

In the absence of fixed costs, we would define the probability of

$\dagger$ Since we include time dummies in the hours equation, we cannot use national unemployment for identification. 
a worker being discouraged from participation by search costs as $\dagger$

$$
\operatorname{Pr}\left[h^{*}(w)>0, I<0\right]
$$

That is to say, the individual would like to work at her market wage but she does not participate because the costs of search outweigh the expected benefits. However, in the presence of fixed costs, Equation (19) will overestimate the number of workers discouraged because of search costs. It would be useful to decompose the total "discouraged" effect into one due to fixed costs and one due to search costs but since both fixed costs and search costs are unobserved, this is not directly possible. However, assume that at the peak of the business cycle, represented by demand conditions $D_{i}$, jobs are so easy to locate that search costs are irrelevant and that only fixed costs affect participation decisions. $\$$ Then for an individual facing a current wage $w_{i}$ and current demand conditions $d_{i}$, we have the decomposition (an identity):

$$
\begin{aligned}
& \operatorname{Pr}\left[h_{i}^{*}\left(w_{i}\right)>0, I_{i}<0 \mid w_{i}, d_{i}\right] \equiv \operatorname{Pr}\left[h_{i}^{*}\left(w_{i}\right)>0, I_{i}<0 \mid w_{i}, D_{i}\right] \\
& \quad+\operatorname{Pr}\left[h_{i}^{*}\left(w_{i}\right)>0, I_{i}<0 \mid w_{i}, d_{i}\right]-\operatorname{Pr}\left[h_{i}^{*}\left(w_{i}\right)>0, I_{i}<0 \mid w_{i}, D_{i}\right] .
\end{aligned}
$$

The first term on the right-hand side is evaluated at peak demand conditions and therefore measures only the effect of fixed costs. The remaining terms measure the effect of search costs on participation. We note that since some individuals will be discouraged from searching even under peak demand conditions, use of Equation (20) provides a lower bound on the importance of search costs relative to fixed costs.§

$\dagger$ With a non-degenerate wage offer distribution in the Burdett-Mortensen model, we define a discouraged worker as an individual who does not satisfy $I>0$ but who would search in the absence of search costs. A wage offer distribution is defined over the range $\left[w_{l}, w_{u}\right]$. In the absence of search costs, the individual searches if $w_{u}>w_{i}$, where $w_{i}$ is the labour supply reservation wage. Thus, the probability of a worker being discouraged is given by $\operatorname{P}=\operatorname{Pr}\left[w_{u}>w_{\imath}, I<0\right]$. Of course, since this requires knowledge of the support of the wage distribution, it is of limited practical use. Instead, we use the conservative (but observable) measure $P=\operatorname{Pr}[w m<w i, I<0]=\operatorname{Pr}[h(w m)>0, I<0]$, where $w m$ is the mean of the wage offer distribution. Thus, this measure coincides with the measure used in the text.

\$ For a more precise version of this statement, see Appendix A.

$\S$ Since we want to measure the number of discouraged workers due to fixed and search costs separately at wage $w$, we do not adjust $w$ when moving from demand conditions $d$ to $D$. 


\section{Empirical results}

\subsection{DATA AND ESTIMATION STRATEGY}

A sample of married couples of working age is drawn from the Family Expenditure Survey (FES) for each of the years 1981-1984. Thus, we have a time series of independent cross-sections since the FES is based on a new random sample each year. Moreover, the FES allows us to identify the quarter in which the household was interviewed. We note that the FES collects extensive consumption data as well as data on weekly hours. A brief description of the sample properties is provided in Appendix B. Hours are measured as normal weekly hours of work for those currently in employment. The wage rate $(w)$ is the real marginal hourly wage rate, accounting for taxes and earnings-related benefits. $\dagger$ The "other income" term $\mu$ is, as described in the previous section, constructed from the budget identity $(\mu=C-w h)$ where $C$ is real household non-durable consumption and $w$ is the real marginal wage. It is therefore measured in real $£ s$ per week.

The economic position variable in the survey identifies job seekers as well as those in employment and those out of the labour force. Job seekers are those who are classified as "out of work but seeking employment”. The sample consists of 13911 adult couples including 8249 working women and 592 job seekers.

Our estimation strategy proceeds as follows. First, we estimate the wage equation using the Heckman selectivity correction. Second, we run a reduced-form regression for other income. We then estimate the structural hours equation by maximizing Equation (13), assuming that the error terms follow a joint normal distribution. In the hours equation we control for the endogeneity of the marginal wage and other income by including reduced-form residuals defined as the difference between these variables and their predicted values. The corresponding asymptotic normal $t$ values of the coefficients on these residual terms are the respective exogeneity tests (see Smith and Blundell, 1986). To estimate the participation equation, we control for the endogeneity of the marginal wage and other income by using predicted values in the $I_{i}$ index. (The respective exclusion restrictions are discussed in Section 3.3 above.) This procedure again produces consistent parameter estimates. Consistent estimates of the variance-covariance matrix are obtained using results from Pagan (1986).

$\dagger$ We deflate wages and other income by the relevant monthly price index.

$\ddagger$ The selection index is a function of the business-cycle and individual variables. 


\subsection{RESULTS}

The presentation of our empirical results follows the sequential nature of the estimation strategy outlined above. The reducedform equations relating to other income, wage and labour force participation are presented in Table 1 . In viewing Table 1 it is of particular interest to examine the role of the business-cycle variables. In the wage equation all of the business-cycle variables are significant and, except for redundancies, have the expected sign. Since theory predicts that these variables do not belong in the labour supply equation, they clearly aid in identification of the within-period preferences. From the estimates of the participation equation in column (3) of Table 1, we note again that the businesscycle variables are jointly significant (the $\chi^{2}(4)$ value being 63.08$)$. We defer discussing the signs of the business-cycle coefficients until we consider the structural probit estimates in Table 2. Thus, demand variables continue to enter a reduced-form participation equation when we correctly classify job seekers as labour force participants.

Column (1) of Table 2 contains the estimates of the corresponding structural labour force participation equation, conditional on the wage and other income, when we do not control for time effects, while column (2) contains the respective parameter estimates when we enter time dummies. In column (1) we have introduced two national unemployment rates since time dummies are not included. The short-term rate refers to the proportion of those unemployed with duration less than one year, while the long-term rate refers to the remaining unemployed. We see that the business-cycle variables have overall the expected sign and are jointly significant at standard confidence intervals. Moreover, their significance is not diminished by the inclusion of quarterly time dummies. It should be pointed out that with business-cycle variables excluded, the time dummies are much more significant. $\dagger$

In Table 3 we present the employment index (see Equation (9)). Once again, the business-cycle variables generally have their expected sign. The inclusion of wage and other income variables in column (2) has little impact on these results. It is possible to argue that the results obtained in Table 3 are spurious and the sample separation information of non-workers into job seekers and non-participation is incorrect. To investigate such potential misspecification we randomly assigned (with replacement) women in the non-worker group to the seeker category until we had the same

$\dagger$ One might argue that the business-cycle variables capture the effect of the employment status of the husband and this simply represents non-separability in preferences. We experimented with including a husband employed dummy and none of our conclusions changed. 
TABLE 1 The reduced-form models

\begin{tabular}{lccc}
\hline & $\begin{array}{c}(1) \\
\text { Log marginal } \\
\text { wage }\end{array}$ & $(2)$ & $\begin{array}{c}(3) \\
\text { Oabour force } \\
\text { participation }\end{array}$ \\
\hline Constant & $\begin{array}{c}0.38206 \\
(0.0404)\end{array}$ & $\begin{array}{c}57.93209 \\
(5.8121)\end{array}$ & $\begin{array}{c}1.47832 \\
(0.1184)\end{array}$
\end{tabular}

Number of children:

K1 (0-2 years)

$\begin{array}{cc}11.90322 & -0.42390 \\ (3.7810) & (0.0895) \\ 7.90416 & -0.16033 \\ (2.8572) & (0.0607) \\ 5.43608 & -0.14397 \\ (1.4164) & (0.0289) \\ 8.11274 & -0.02710 \\ (1.1798) & (0.0234)\end{array}$

Dummy variable for age of youngest child: DK1 (0-2 years)

DK2 (3-4 years)

DK3 (5-10 years)

DK4 (11 years and over)

$\begin{array}{cc}17.40789 & -1.21586 \\ (4.9456) & (0.1116) \\ 18.38614 & -0.06709 \\ (4.1255) & (0.0855) \\ 10.26790 & -0.46654 \\ (2.8497) & (0.0583) \\ 14.48247 & -0.17138 \\ (2.3960) & (0.0481)\end{array}$

Wife's demographic variables:

$\begin{array}{lccc}\text { Age } & 0.01816 & 11.90884 & -0.20003 \\ & (0.0126) & (1.7623) & (0.0358) \\ \text { Age }^{2} & -0.00441 & -3.69155 & -0.02849 \\ & (0.0079) & (1.1444) & (0.0231) \\ \text { Ed (leaving age) } & 0.96104 & -4.90362 & 1.03015 \\ & (0.0489) & (6.7142) & (0.1374) \\ \text { Ed }^{2} & -0.06983 & 27.97443 & -0.32523 \\ & (0.0761) & (1.5230) & (0.2562) \\ \text { Age }^{*} \mathrm{Ed} & 0.06659 & 11.73478 & -0.11908 \\ & (0.0260) & (3.7342) & (0.0777) \\ \left.\text { Age }^{*} \mathrm{Ed}\right)^{2} & -0.06238 & -0.61547 & -0.07003 \\ & (0.0359) & (5.1197) & (0.1102)\end{array}$

Husband's demographic variables:

MAge

$\begin{array}{ccc}0.00981 & 5.45363 & -0.04543 \\ (0.0114) & (1.5290) & (0.0313) \\ 0.00024 & -2.31061 & -0.06187 \\ (0.0060) & (0.7910) & (0.0159)\end{array}$


TABLE 1 continued

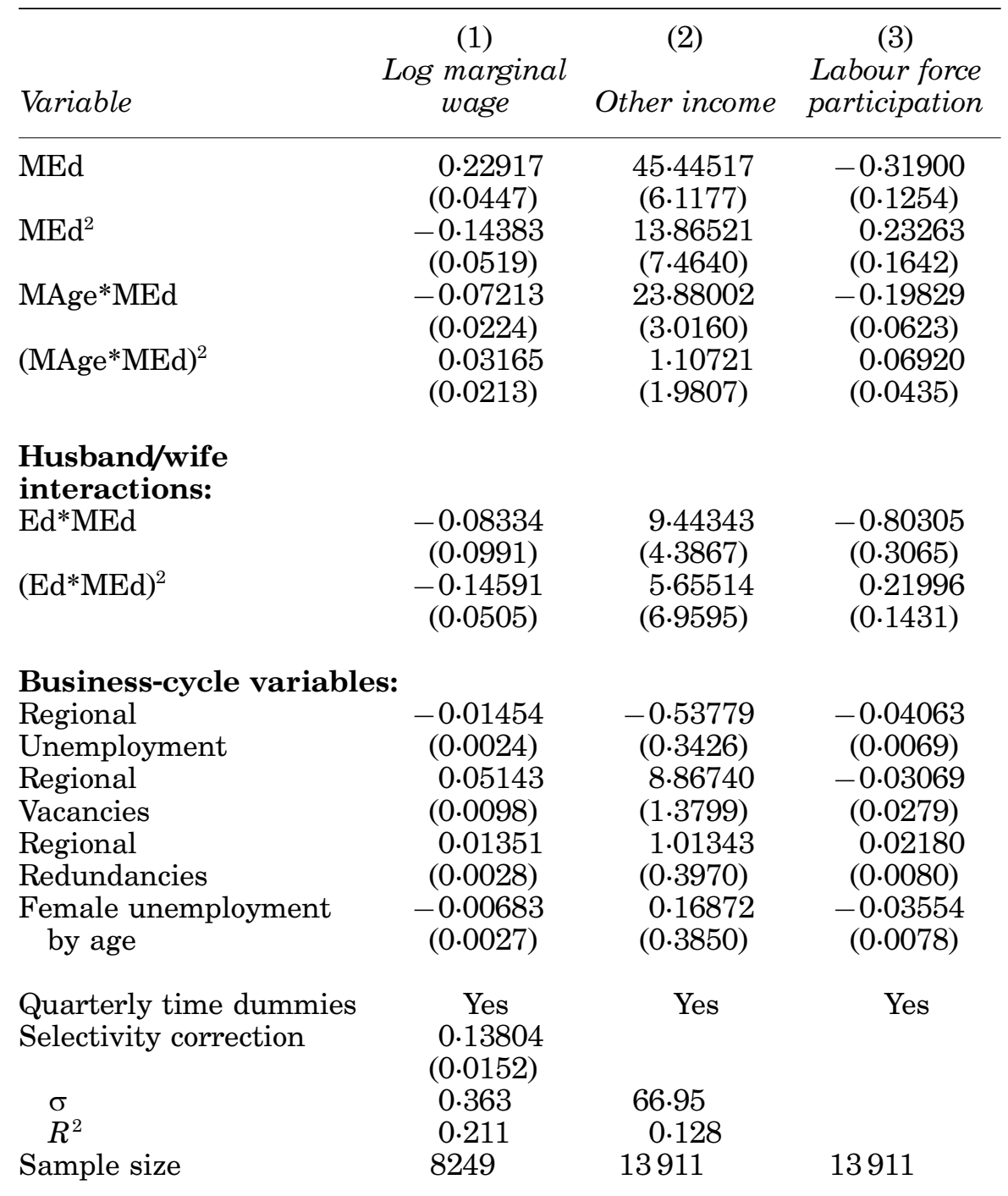

Note: Standard errors in parentheses.

proportion of seekers as in the actual data. We then re-estimated the conditional employment equation. However, as the women in each random sample should differ in their labour force attachment from the actual seekers, we would expect to find business-cycle variables less significant in these new estimates of the employment probability index than in our Table 3 estimates. In our experiment we took 10 random samples from the total set of seekers and nonparticipants. In only three out of the 10 new samples was the 
TABLE 2 Labour force participation index

(1) (2)

Time dummies Time dummies

Variable excluded

Constant

$\begin{array}{cc}2.3342 & 1.7141 \\ (0.3939) & (0.1371)\end{array}$

Number of chidren:

K1 (0-2 years)

$\begin{array}{cc}-0.1835 & -0.1634 \\ (0.0583) & (0.0584) \\ -0.2130 & -0.2076 \\ (0.0583) & (0.0585) \\ -0.1571 & -0.1494 \\ (0.0287) & (0.0289) \\ -0.0026 & 0.0089 \\ (0.0250) & (0.0254)\end{array}$

K2 (3-4 years)

K3 (5-10 years)

K4 (11 years and over)

0.0089
$(0.0254)$
Age of youngest child (dummy variable):

DK1 (0-2 years)

DK2 (3-4 years)

DK3 (5-10 years)

DK4 (11 years and over)

\section{Female age:}

Age

$\mathrm{Age}^{2}$

Wage and income variables:

$\ln \hat{w}$

$\hat{\mu}$ (£s per week)

\section{Business-cycle variables:}

Regional unemployment

Regional vacancies

Regional redundancies

Female unemployment by age

$\begin{array}{cc}-1.2504 & -1.2384 \\ (0.0821) & (0.0833) \\ -0.9026 & -0.8787 \\ (0.0852) & (0.0858) \\ -0.3572 & -0.3489 \\ (0.0600) & (0.0602) \\ -0.0506 & -0.0353 \\ (0.0518) & (0.0523)\end{array}$

$\begin{array}{cc}-0.2654 & -0.2644 \\ (0.0275) & (0.0288) \\ -0.0867 & -0.0809 \\ (0.0193) & (0.0199)\end{array}$

$\begin{array}{cc}0.6435 & 0.6441 \\ (0.0729) & (0.0741) \\ -0.0069 & -0.0080 \\ (0.0010) & (0.0011)\end{array}$

$\begin{array}{cc}-0.0107 & -0.0200 \\ (0.0072) & (0.0069) \\ 0.0347 & 0.0153 \\ (0.0274) & (0.0291) \\ 0.0028 & -0.0116 \\ (0.0085) & (0.0082) \\ -0.0274 & -0.0345 \\ (0.0074) & (0.0077)\end{array}$


TABLE 2 continued

(1)

\begin{tabular}{lcc} 
Variable & $\begin{array}{c}\text { Time dummies } \\
\text { excluded }\end{array}$ & $\begin{array}{c}\text { Time dummies } \\
\text { included }\end{array}$ \\
\hline Long-run employment & -0.1280 & - \\
Short-run employment & $(0.0632)$ & - \\
& -0.0083 & \\
$\rho$ (correl with labour supply) & $(0.0298)$ & 0.4236 \\
& 0.4379 & $(0.0662)$ \\
$\chi_{1}^{2}$ & $(0.0645)$ & $33.04(4)$ \\
$\chi_{2}^{2}$ & $39.1(6)$ & $38.86(15)$
\end{tabular}

Notes: Standard errors in parentheses.

Column (2) contains 15 quarterly dummies.

$\chi_{1}^{2}$ is a joint test of excluding the business-cycle variables.

$\chi_{2}^{2}$ is a joint test of excluding the time dummies in column (2).

Degrees of freedom for the $\chi^{2}$ tests in parentheses.

coefficient for female unemployment by age significantly negative ( $P$-value less than 0.05) and in only one of the 10 new samples was the regional unemployment coefficient significant. As a result, we can assume that our model is picking up systematic effects relating to business-cycle factors for those seeking work.

Finally, Table 4 contains the labour supply parameter estimates. The estimates in column (1) are based on the corresponding participation equation in column (1) of Table 2 in which businesscycle variables alone are included. The estimates in column (2) are based on the participation equation, which also includes time dummies. Before summarizing these results in terms of the underlying elasticities and properties over the business cycle, we turn briefly to an interpretation of the labour supply parameters themselves.

We see that growing older and having a child of 2 years or younger has a significant effect on the $\alpha_{0}$ term. Moreover, we see that additional children of all ages (but the oldest) raise the marginal budget share of leisure $\beta_{i}$ as does growing older. (Note that labour supply is decreasing in $\beta$, see Equation (14).) The coefficients for the age of the youngest child dummy variables indicate that $\beta$ increases in the presence of a youngest child less than 11 years old. We also see that $\beta$ is increasing in $\log w$, causing labour supply to be less forward-sloping than it would be in the (separable) LES case where $\beta$ does not depend on $w$. The coefficients and standard errors on the wage and virtual income residuals indicate the necessity of treating the wage and virtual income as endogenous. 
TABLE 3 The employment index model

\begin{tabular}{lcc}
\hline Variable & $(1)$ & $(2)$ \\
\hline Constant & 2.6913 & 2.2468 \\
& $(0.7209)$ & $(0.7574)$
\end{tabular}

Age of youngest child:

DK1 (0-2 years)

DK2 (3-4 years)

$-0.8736 \quad-0.9534$

$(0.0677) \quad(0.0924)$

DK3 (5-10 years)

$-0.2441$

$-0.3276$

DK4 (11 years and over)

$(0.0976) \quad(0.1169)$

$-0.0922 \quad-0.1596$

$(0.0651) \quad(0.0831)$

$0.0951 \quad 0.0219$

$(0.0678) \quad(0.0877)$

Female demographics: Age

$\begin{array}{cc}0.0384 & 0.0074 \\ (0.0346) & (0.0399) \\ 0.2398 & -0.1472 \\ (0.1189) & (0.3378)\end{array}$

Business-cycle variables:

Regional unemployment

$\begin{array}{cc}-0.0467 & -0.0378 \\ (0.0133) & (0.0141) \\ -0.0899 & -0.1311 \\ (0.0394) & (0.0455) \\ -0.0019 & -0.0102 \\ (0.0154) & (0.0159) \\ -0.0369 & -0.0284 \\ (0.0089) & (0.0099) \\ -0.0436 & -0.0147 \\ (0.1189) & (0.1203) \\ 0.0881 & 0.0584 \\ (0.0567) & (0.0585)\end{array}$

Regional vacancies

Regional redundancies

Female unemployment by age

Long-term unemployment

Short-term unemployment

$(0.0567)$

0.0584
$(0.0585)$

Wage and income variables:

\begin{tabular}{lrr}
$\ln \hat{w}$ & - & 0.4641 \\
$\hat{\mu}$ & - & $(0.3737)$ \\
$\ln L$ & -1967.83 & 0.0021 \\
& & $-196017)$ \\
\hline
\end{tabular}

Note: Standard errors in parentheses.

\subsection{ELASTICITIES AND SIMULATIONS}

In Table 5 we describe the properties of the labour supply model. First, we note that all the compensated labour supply elasticities 
TABLE 4 The labour supply model

\begin{tabular}{|c|c|c|}
\hline Variable & $\begin{array}{c}(1) \\
\text { Time dummies } \\
\text { excluded in } \\
\text { selection }\end{array}$ & $\begin{array}{c}(2) \\
\text { Time dummies } \\
\text { included in } \\
\text { selection }\end{array}$ \\
\hline \multicolumn{3}{|c|}{$\alpha_{o}$ Variables: } \\
\hline Constant & $\begin{array}{c}84 \cdot 384 \\
(2 \cdot 487)\end{array}$ & $\begin{array}{c}84.592 \\
(2 \cdot 485)\end{array}$ \\
\hline \multicolumn{3}{|c|}{ Age of youngest child } \\
\hline DK1 & $\begin{array}{c}9 \cdot 395 \\
(2 \cdot 446)\end{array}$ & $\begin{array}{c}9 \cdot 309 \\
(2 \cdot 440)\end{array}$ \\
\hline DK2 & $\begin{array}{c}4.453 \\
(3.667)\end{array}$ & $\begin{array}{c}4 \cdot 349 \\
(3 \cdot 658)\end{array}$ \\
\hline DK3 & $\begin{array}{c}-1.844 \\
(1.981)\end{array}$ & $\begin{array}{c}-1.821 \\
(1.980)\end{array}$ \\
\hline $\mathrm{DK} 4$ & $\begin{array}{c}-0.549 \\
(1.745)\end{array}$ & $\begin{array}{c}-0.491 \\
(1.743)\end{array}$ \\
\hline Female age & $\begin{array}{c}7.453 \\
(0.768)\end{array}$ & $\begin{array}{c}7.437 \\
(0.768)\end{array}$ \\
\hline \multicolumn{3}{|c|}{$\alpha_{q}$ Variables: } \\
\hline Constant & $\begin{array}{r}-40 \cdot 073 \\
(5 \cdot 138)\end{array}$ & $\begin{array}{r}-40 \cdot 142 \\
(5 \cdot 139)\end{array}$ \\
\hline \multicolumn{3}{|c|}{ Number of children } \\
\hline $\mathrm{K} 1$ & $\begin{array}{r}-12 \cdot 325 \\
(5 \cdot 226)\end{array}$ & $\begin{array}{r}-12 \cdot 252 \\
(5 \cdot 234)\end{array}$ \\
\hline $\mathrm{K} 2$ & $\begin{array}{c}-12.924 \\
(3.897)\end{array}$ & $\begin{array}{r}-12.830 \\
(3.897)\end{array}$ \\
\hline K3 & $\begin{array}{r}-10.381 \\
(1.723)\end{array}$ & $\begin{array}{r}-10 \cdot 313 \\
(1.724)\end{array}$ \\
\hline K4 & $\begin{array}{c}5.010 \\
(1.072)\end{array}$ & $\begin{array}{c}5.050 \\
(1.070)\end{array}$ \\
\hline \multicolumn{3}{|c|}{ Budget share $(\beta)$ coefficients: } \\
\hline Constant & $\begin{array}{c}0.2725 \\
(0.0076)\end{array}$ & $\begin{array}{c}0.2715 \\
(0.0076)\end{array}$ \\
\hline Age & $\begin{array}{c}0.0428 \\
(0.0037)\end{array}$ & $\begin{array}{c}0.0426 \\
(0.0037)\end{array}$ \\
\hline $\mathrm{Age}^{2}$ & $\begin{array}{c}0.0082 \\
(0 \cdot 0011)\end{array}$ & $\begin{array}{c}0.0081 \\
(0.0011)\end{array}$ \\
\hline$\beta_{1}(\mathrm{DK} 1)$ & $\begin{array}{c}0.1250 \\
(0.0144)\end{array}$ & $\begin{array}{c}0.1236 \\
(0.0144)\end{array}$ \\
\hline$\beta_{2}(\mathrm{DK} 2)$ & $\begin{array}{c}0.0898 \\
(0.0183)\end{array}$ & $\begin{array}{c}0.0886 \\
(0.0183)\end{array}$ \\
\hline$\beta_{3}(\mathrm{DK} 3)$ & $\begin{array}{c}0.0440 \\
(0.0105)\end{array}$ & $\begin{array}{c}0.0439 \\
(0.0105)\end{array}$ \\
\hline$\beta_{4}(\mathrm{DK} 4)$ & $\begin{array}{c}0.0149 \\
(0.0082)\end{array}$ & $\begin{array}{c}0.0152 \\
(0.0081)\end{array}$ \\
\hline
\end{tabular}


TABLE 4 continued

\begin{tabular}{lcc}
\hline Variable & $\begin{array}{c}(1) \\
\text { Time dummies } \\
\text { excluded in } \\
\text { selection }\end{array}$ & $\begin{array}{c}\text { Time dummies } \\
\text { included in } \\
\text { selection }\end{array}$ \\
\hline$\beta_{w}$ (log wage) & 0.1219 & 0.1224 \\
& $(0.0059)$ & $(0.0059)$ \\
Wage and other income residuals: & & \\
$\hat{u}_{w}$ & 0.0817 & 0.0810 \\
$\hat{u}_{\mu}$ & $(0.0058)$ & $(0.0058)$ \\
$\sigma$ & -0.00071 & -0.00071 \\
& $(0.00002)$ & $(0.00002)$ \\
Quarterly time dummies included & 0.0752 & 0.0750 \\
& $(0.0030)$ & $(0.0030)$ \\
Yes & Yes & Yes \\
\hline
\end{tabular}

Note: Standard errors in parentheses.

TABLE 5 Elasticities for model 1

\begin{tabular}{lccccc}
\hline & \multicolumn{3}{c}{ WORKERS } & & NON-WORKERS \\
\cline { 2 - 3 } \cline { 5 - 5 } & $\begin{array}{c}\text { Uncompensated } \\
\text { hours }\end{array}$ & $\begin{array}{c}\text { Compensated } \\
\text { hours }\end{array}$ & $\begin{array}{c}\text { Compensted } \\
\text { leisure }\end{array}$ & & $\begin{array}{c}\text { Compensated } \\
\text { leisure }\end{array}$ \\
\hline $\mathrm{M}_{25}$ & -0.063 & 0.291 & -0.233 & & -0.195 \\
$\mathrm{M}_{50}$ & 0.107 & 0.506 & -0.186 & & -0.172 \\
$\mathrm{M}_{75}$ & 0.383 & 0.889 & -0.145 & & -0.148 \\
$\mathbf{M e a n}$ & 0.307 & 0.810 & -0.195 & & -0.175 \\
\hline
\end{tabular}

are positive, $\dagger$ implying that the estimated model satisfies the restrictions of economic theory everywhere in the sample of workers. When we compute the compensated leisure elasticities for the non-workers (evaluated at an imputed wage), they too have the correct (negative) sign. $\$$ Moreover, the elasticities are relatively high. This suggests that a proper treatment of the wage and other income variables as endogenous is important. In fact when we do not instrument the wage and other income, we get much more

$\dagger$ The table shows the median and the 1st and 3rd quartiles. In fact all compensated elasticities have the right sign.

\$Clearly, we cannot compute labour supply elasticities since labour supply is zero. 


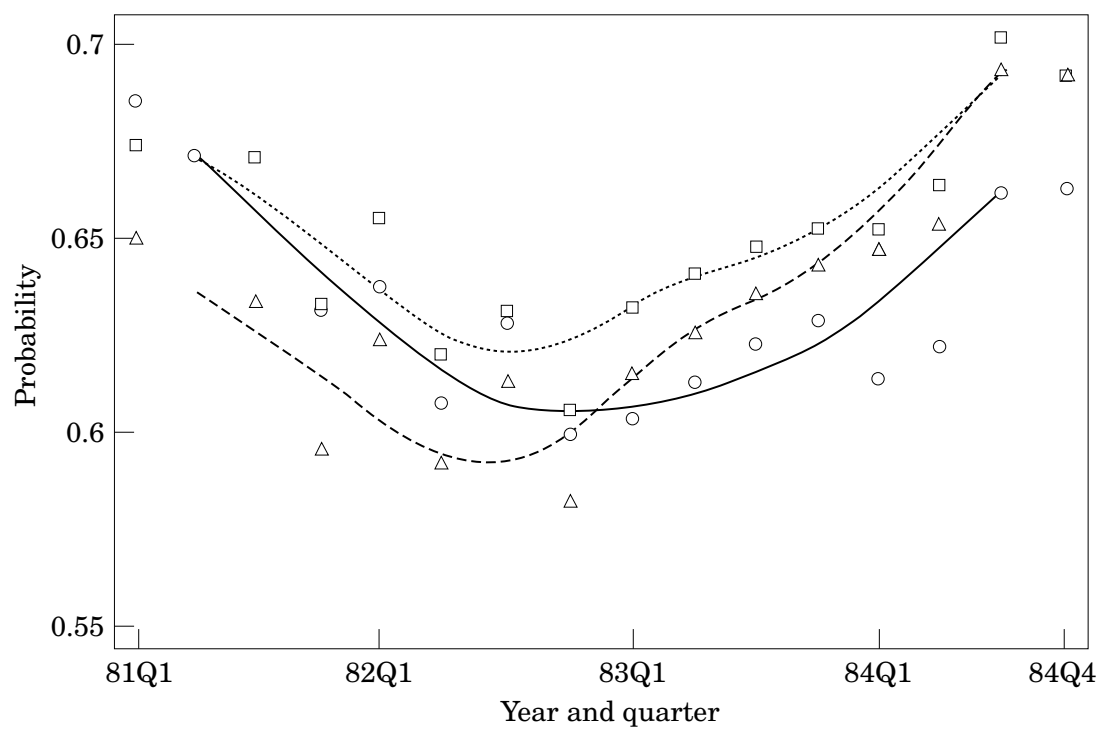

FIGURE A. Predicted probability of participation with time dummies. PeFull—at sample values $(-\bigcirc)$; Pewd-wage and business-cycle variables fixed at mean (------ $\square)$; Ped-business-cycle variables fixed at mean $(-\cdots-\triangle)$.

backward-bending labour supply behaviour and much less theory consistency.

We now turn to two simulations. First, we consider the relative importance of the wage and the business-cycle variables in explaining the change of participation over time. $\dagger$ We present results for both the model with quarterly time dummies in the participation equation (Figure A) and the model without the time dummies (Figure B). In these graphs the line marked PeFull is a smoothed curve describing the predicted probability of participation over the entire sample. Ped is the curve illustrating the predicted probability of participation when the business-cycle variables are kept constant at the overall mean. Finally, the Pewd curve keeps both the wage and the business-cycle variables constant. Since Pewd does not hold the other income variable $(\mu)$ constant, and since the latter is cyclical, the Pewd graph in Figure B is not constant and reflects this cyclicality. $\$$ Note that our sample covers the 1981-1984 period. The recession started towards the end of 1980 and was at its deepest by mid-1982. Real wages were in slight decline from

$\dagger$ Note that Burdett et al. (1984) also examine the effect of wages on the participation decision.

$\$$ Note also that demographic changes will also induce variability over time. Moreover, in Figure A Pewd moves with the time dummies that are included in the equation. 


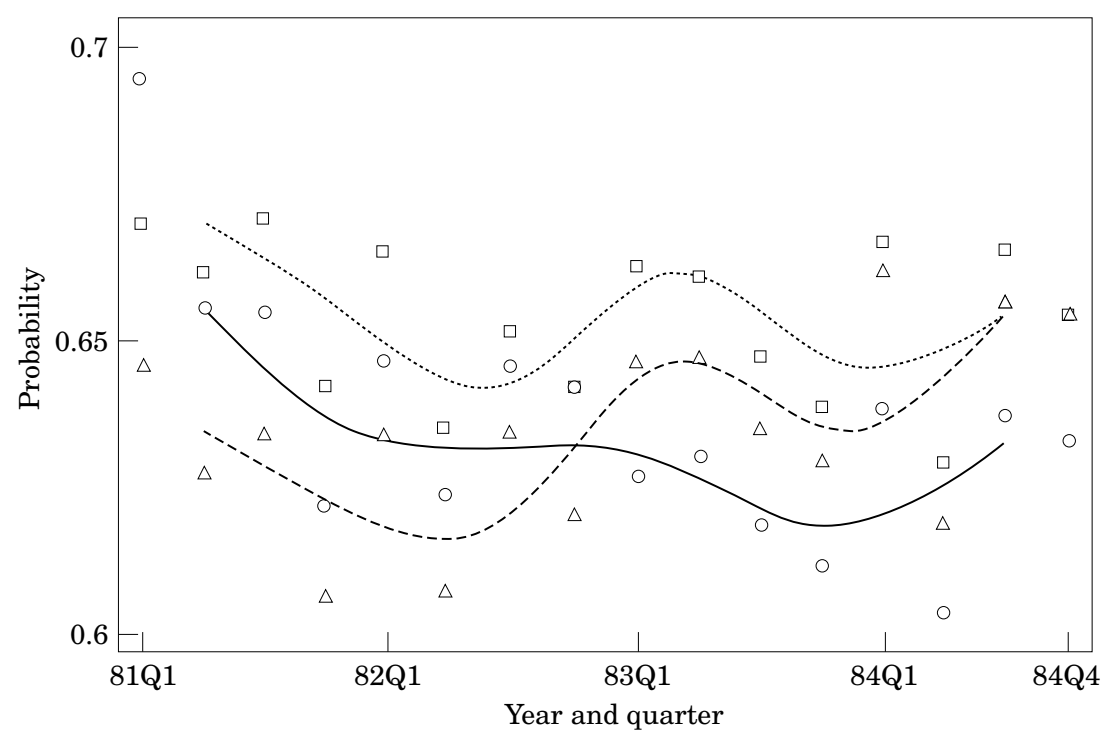

FIGURE B. Predicted probability of participation with no time dummies. PeFull—at sample values (- $(-)$; Pewd-wage and business-cycle variables fixed at mean (------ $\square)$; Ped-businesscycle variables fixed at mean $(---\triangle)$.

1980 to mid-1982 and then they started rising rapidly without a significant drop in unemployment. This explains why fixing the business-cycle variables induces an over-prediction of participation (compare PeFull and Ped). Obviously, the effect is more marked when we exclude time dummies, letting the business-cycle variables and wages explain all the time-series variation. Overall, these graphs show that the business-cycle variables explain a large component of the time-series variability in participation.

The second simulation we perform relates to computing the relative importance of fixed costs and of search costs. As explained in Section 3.4 we achieve this by computing the proportion of implied discouraged workers at sample values and at peak demand conditions. For regional unemployment, regional redundancies and female unemployment by age, we take the sample minima. Since it is not clear how vacancies actually behave at good times we decided to regress them on a quadratic function of the other three variables and predict the regional vacancy rate using this regression and setting the three right-hand side variables to their sample minima. The resulting peak demand conditions were: regional unemployment $6 \cdot 2 \%$, female unemployment by age $1.2 \%$ and regional redundancy rate $1.22 \%$. The model with no time dummies implies that $24.4 \%$ of workers are "discourged" $-14.5 \%$ are discouraged due to fixed costs and $9.9 \%$ are discouraged by 
search costs. The behaviour of the remaining $12 \%$ out of a total of $36.4 \%$ non-participants can be explained by the standard reservation wage argument. The results for the model with time dummies are $24.1 \%$ discouraged $-17.9 \%$ are due to fixed costs and $6.2 \%$ are due to search costs. As we would expect, this model implies a smaller role for search costs since some of the variability in the business-cycle variables is absorbed by the time dummies. Nevertheless, the overall picture is quite similar. Hence, we estimate that at least $6.2 \%$ of all individuals are discouraged due to costs of search, which is a lower bound since even under peak conditions, a number of individuals would still face significant search costs.

\section{Conclusions}

In this paper we develop and estimate a model of labour supply which allows for search unemployment and discouraged workers. We show that a standard two-stage budgeting approach to estimating within-period preferences is appropriate in this framework. We use a flexible functional form to estimate labour supply behaviour. We find that labour supply behaviour is relatively elastic with a mean elasticity of $0 \cdot 31$. Moreover, we find that the restriction on the sign of the Slutsky substitution terms is satisfied for all workers and all non-workers in our sample.

Our theoretical specification also predicts that business-cycle variables belong in a participation equation conditional on market wages and other income. We find that our prediction is in fact borne out by the data and that these variables play a substantial role in explaining the variability in participation over time. Moreover, the introduction of these business-cycle variables significantly reduces temporal instability in the participation equation. Finally, we show that our model can estimate the relative importance of search costs and fixed costs of participation. We find that approximately $15 \%$ of individuals are discouraged from participating by fixed costs and that approximately $10 \%$ are discouraged from participating by search costs.

\section{Acknowledgements}

We should like to thank David Card, Alun Duncan, Christian Gourieroux, Ed Green, George Jakubson, Guy Laroque, Thierry Magnac, Dale Mortensen, Chris Pissarides, Geert Ridder, Gary Solon and Ian Walker for helpful comments. Finance for this research, provided by the ESRC and Department of Employment, is gratefully acknowledged. John Ham would like to thank the 
Institute for Policy Analysis, SSHRC, Canada and the National Science Foundation (grants SBR-951-2001 and SES-921-3310), for support. The data for this research were provided by the Department of Employment. All errors remain our responsibility.

\section{References}

Altonji, J.G. (1982). The intertemporal sustitution model of labour market fluctuations: an empirical analysis. Review of Economic Studies, 49, 783-824.

Ashenfelter, O. (1980). Unemployment as disequilibrium in a model of aggregate labor supply. Econometrica, 48, 547-564.

Blundell, R.W. (1986). Econometric approaches to life-cycle labour supply and commodity demands. Econometric Reviews, 5, 89-146.

Blundell, R.W., Ham, J. \& Meghir, C. (1987). Unemployment and female labour supply. Economic Journal, 97, 44-64.

Blundell, R.W. \& Meghir, C. (1986). Selection criteria for a microeconometric model of labour supply. Journal of Applied Econometrics, 1, 55-81.

Blundell, R.W. \& Walker, I. (1986). A life cycle consistent empirical model of labour supply using cross section data. Review of Economic Studies, 53, 539-558.

Burdett, K., Kiefer, N.M., Mortensen, D.T. \& Neumann, G. (1984). Earnings, unemployment and the allocation of time over time. Review of Economic Studies, LI, 559-578.

Burdett, K. \& Mortensen, D.T. (1978). Labour supply under uncertainty. In R.G. Ehrenberg, Ed. Research in Labor Economics, 12. Greenwich, Connecticut: JAI Press..

Cogan, J.F. (1980a). Married women's labour supply: a comparison of alternative estimation procedures. In J. Smith, Ed. Female Labour Supply. Princeton: Princeton University Press.

Cogan, J.F. (1980b). Labour supply with costs of market entry. In J. Smith, Ed. Female Labour Supply. Princeton: Princeton University Press.

Cogan, J.F. (1981). Fixed costs and labor supply. Econometrica, 49, 945-964.

Ehrenberg, R. \& Smith, R. (1988). Modern Labor Economics: Theory and Public Policy, 3rd edition. Scott, Foreman and Co.

Flinn, C.J. \& Heckman, J.J. (1983). Are unemployment and out of the labor force behaviorally distinct labor force states? Journal of Labour Economics, 1, 28-42.

Ham, J. (1982). Estimation of a labor supply model with censoring due to unemployment and underemployment. Review of Economic Studies, 49, 335354.

Ham, J. (1986a). Testing whether unemployment represents life-cycle labor supply behavior. Review of Economic Studies, LIII, 559-578.

Ham, J. (1986b). On the interpretation of unemployment in empirical labour supply analysis. In R.W. Blundell \& I. Walker, Eds. Unemplyment, Search and Labour Supply. Cambridge: Cambridge University Press.

Hausman, J.A. (1980). The effect of wages, taxes and fixed costs on women's labor force participation. Journal of Public Economics, 14, 161-194.

Heckman, J.J. (1979). Sample selection bias as a specification error. Econometrica, 47, 153-162.

Heckman, J.J. \& MaCurdy, T.E. (1980). A life-cycle model of female labor supply. Review of Economic Studies, Special Issue, 47, 47-74.

MaCurdy , T.E. (1983). A simple scheme for estimating an intertemporal model of labor supply and consumption in the presence of taxes and uncertainty. International Economic Review, 24, 265-289.

Mroz, T.A. (1987). The sensitivity of an empirical model of married women's hours of work to economic and statistical assumptions. Econometrica, 55, 765-800. 
Nakamura, A. \& Nakamura, M. (1981). A comparison of the labour force behaviour of married women in the United States and Canada, with special attention to the impact of income taxes. Econometrica, 49, 451-489.

Pagan, A. (1986). Two stage and related estimators and their applications. Review of Economic Studies, 53, 517-538.

Smith, R.J. \& Blundell, R.W,. (1986). An exogeneity test for the simultaneous equation Tobit model. Econometrica, 54, 679-685.

\section{Appendix A}

Greater intuition concerning the model defined by Equations (1)-(5) can be gained by considering a somewhat simplified optimization problem. In particular, maintain our previous assumptions but follow Burdett and Mortensen (1978) by assuming that $\alpha_{o}=0$ and that the consumer satisfies the static budget constraint $y+w h_{t}=$ $C_{t}$ in each period. In this case, the value functions are stationary and we can solve for stationary (and informative) decision rules.

Let $\varphi=(1+\rho)^{-1}$ and define $U^{o}$ as $(1+\rho)$ times within-period utility in non-participation, $U^{o}=(1+\rho) U(T, y)$, and $U^{s}$ as $(1+\rho)$ times within-period utility while searching, $U^{s}=(1+\rho) U(T-s$, $y-c)<U^{o}$. Further, define $U^{e}$ as $(1+\rho)$ times utility while working, where $y+w h_{t}=c_{t}$. Then Equations (1), (3) and (4) become

$$
\begin{aligned}
& \rho V^{o}=U^{o} \\
& \rho V^{s}=U^{s}+\alpha_{s}\left(V^{e}-V^{s}\right) \quad \text { and } \\
& \rho V^{e}=U^{e}+\delta\left(V^{s}-V^{e}\right)
\end{aligned}
$$

respectively (see equations (20a)-(20c) of Burdett and Mortensen, 1978). Solving for $V^{s}$ yields

$$
\rho V^{s}=\frac{(\rho+\delta)}{\left(\rho+\alpha_{s}+\delta\right)} U^{s}+\frac{\alpha_{s}}{\left(\rho+\alpha_{s}+\delta\right)} U^{e}
$$

An individual participates if $V^{s}>V^{o}$, or if

$$
\left(U^{e}-U^{o}\right)-k\left(U^{o}-U^{s}\right)>0
$$

where $k=(\rho+\delta) / \alpha_{s}$.

Recall that $\delta$ is the lay-off rate and $\alpha_{s}$ is the arrival rate of offers when searching. Both will be affected by business-cycle variables 
even when we hold the wage constant in $U^{e}$, and thus the structural participation equation will also vary with these business-cycle variables.

It is straightforward to allow for varying search intensity and a non-degenerate wage offer distribution within the BurdettMortensen framework. The decision rule becomes

$$
\left(U^{*}-U^{o}\right)-\frac{(\rho+\delta)}{\alpha P^{*}}\left(U^{o}-U^{s}\right)>0,
$$

where $U^{*}$ is $(1+\rho)$ times expected current-period utility conditional on working at a wage above the search reservation wage and $P^{*}$ is the probability of a wage offer being above this reservation wage. In Equation (A.6), all variables are evaluated at the optimal search intensity.

Now consider the problem of distinguishing search costs from fixed costs. For clarity and simplicity, assume a degenerate wage offer distribution and a constant search intensity. In this case the probability of a worker being discouraged is given by

$$
\operatorname{Pr}\left[h(w)>0, U^{e}-U^{o}<k\left(U^{o}-U^{s}\right)\right] .
$$

This probability is affected by search costs through $U^{s}$ and by fixed costs through $U^{e}$. However, if we assume that at the peak of the business cycle (represented by demand conditions $D$ in Equation (20)) jobs are so easy to locate that $k$ approaches to zero, then Equation (A.7) becomes

$$
\operatorname{Pr}\left[h(w)>0, U^{e}-U^{o}<0\right],
$$

which depends on fixed costs but not on search costs. Since $k$ will not go to zero even at the peak of the cycle, we are providing a conservative estimate of the importance of search costs relative to fixed costs. 
Appendix B: descriptive statistics across time: means (S.D.)

\begin{tabular}{|c|c|c|c|c|}
\hline & 1981 & 1982 & 1983 & 1984 \\
\hline Gross wage (workers) & $\begin{array}{c}2.656 \\
(1.503)\end{array}$ & $\begin{array}{c}2.569 \\
(1.466)\end{array}$ & $\begin{array}{c}2.778 \\
(1.544)\end{array}$ & $\begin{array}{c}2.769 \\
(1.494)\end{array}$ \\
\hline Marginal wage (workers) & $\begin{array}{c}1.849 \\
(1.072)\end{array}$ & $\begin{array}{c}1.672 \\
(1.015)\end{array}$ & $\begin{array}{c}1.969 \\
(1.122)\end{array}$ & $\begin{array}{c}1.974 \\
(1.043)\end{array}$ \\
\hline Hours (workers) & $\begin{array}{c}25.847 \\
(11.638)\end{array}$ & $\begin{array}{c}25.658 \\
(11.879)\end{array}$ & $\begin{array}{c}25.492 \\
(11.815)\end{array}$ & $\begin{array}{c}25.008 \\
(11.997)\end{array}$ \\
\hline Other income (workers) & $\begin{array}{c}61.938 \\
(63.136)\end{array}$ & $\begin{array}{c}60 \cdot 712 \\
(68 \cdot 175)\end{array}$ & $\begin{array}{c}61.507 \\
(65.171)\end{array}$ & $\begin{array}{c}63.096 \\
(72.454)\end{array}$ \\
\hline Age & $\begin{array}{c}38.951 \\
(10 \cdot 877)\end{array}$ & $\begin{array}{c}38.502 \\
(10.735)\end{array}$ & $\begin{array}{c}38.361 \\
(10.550)\end{array}$ & $\begin{array}{c}39 \cdot 038 \\
(10 \cdot 689)\end{array}$ \\
\hline Age left education & $\begin{array}{c}15 \cdot 836 \\
(2 \cdot 016)\end{array}$ & $\begin{array}{c}15.895 \\
(2.021)\end{array}$ & $\begin{array}{c}15.902 \\
(1.923)\end{array}$ & $\begin{array}{c}15.987 \\
(1.988)\end{array}$ \\
\hline Youngest child $0-2$ & $\begin{array}{c}0.168 \\
(0.432)\end{array}$ & $\begin{array}{c}0.204 \\
(0.461)\end{array}$ & $\begin{array}{c}0.207 \\
(0.471)\end{array}$ & $\begin{array}{c}0.175 \\
(0.425)\end{array}$ \\
\hline Youngest child $3-4$ & $\begin{array}{c}0.101 \\
(0.318)\end{array}$ & $\begin{array}{c}0.124 \\
(0.344)\end{array}$ & $\begin{array}{c}0.133 \\
(0.357)\end{array}$ & $\begin{array}{c}0.134 \\
(0.358)\end{array}$ \\
\hline Youngest child 5-10 & $\begin{array}{c}0.388 \\
(0.698)\end{array}$ & $\begin{array}{c}0.380 \\
(0.675)\end{array}$ & $\begin{array}{c}0.367 \\
(0.658)\end{array}$ & $\begin{array}{c}0.360 \\
(0.662)\end{array}$ \\
\hline Youngest child $11+$ & $\begin{array}{c}0.466 \\
(0.768)\end{array}$ & $\begin{array}{c}0.444 \\
(0.755)\end{array}$ & $\begin{array}{c}0.438 \\
(0.739)\end{array}$ & $\begin{array}{c}0.431 \\
(0.720)\end{array}$ \\
\hline No. children $0-2$ & $\begin{array}{c}0.146 \\
(0.353)\end{array}$ & $\begin{array}{c}0.179 \\
(0.384)\end{array}$ & $\begin{array}{c}0.180 \\
(0.384)\end{array}$ & $\begin{array}{c}0.157 \\
(0.364)\end{array}$ \\
\hline No. children 3-4 & $\begin{array}{c}0.057 \\
(0.232)\end{array}$ & $\begin{array}{c}0.071 \\
(0.257)\end{array}$ & $\begin{array}{c}0.080 \\
(0.271)\end{array}$ & $\begin{array}{c}0.083 \\
(0.277)\end{array}$ \\
\hline No. children 5-10 & $\begin{array}{c}0.203 \\
(0.402)\end{array}$ & $\begin{array}{c}0.182 \\
(0 \cdot 386)\end{array}$ & $\begin{array}{c}0.168 \\
(0.374)\end{array}$ & $\begin{array}{c}0.166 \\
(0.372)\end{array}$ \\
\hline No. children $11+$ & $\begin{array}{c}0.193 \\
(0.395)\end{array}$ & $\begin{array}{c}0.182 \\
(0.386)\end{array}$ & $\begin{array}{c}0.191 \\
(0.393)\end{array}$ & $\begin{array}{c}0.193 \\
(0.395)\end{array}$ \\
\hline Regional unemployment & $\begin{array}{l}10.431 \\
(2 \cdot 658)\end{array}$ & $\begin{array}{l}12 \cdot 015 \\
(2 \cdot 814)\end{array}$ & $\begin{array}{l}12.930 \\
(2 \cdot 883)\end{array}$ & $\begin{array}{c}13.052 \\
(2.878)\end{array}$ \\
\hline Unemployment by age & $6 \cdot 727$ & $6 \cdot 404$ & $7 \cdot 259$ & 7.907 \\
\hline Regional redundancies & $\begin{array}{c}0.088 \\
(2.958)\end{array}$ & $\begin{array}{c}7.597 \\
(2 \cdot 166)\end{array}$ & $\begin{array}{c}6 \cdot 166 \\
(2 \cdot 057)\end{array}$ & $\begin{array}{c}4.458 \\
(1.683)\end{array}$ \\
\hline Regional vacancies & $\begin{array}{c}1.784 \\
(0.496)\end{array}$ & $\begin{array}{c}2.045 \\
(0.505)\end{array}$ & $\begin{array}{c}2.631 \\
(0.418)\end{array}$ & $\begin{array}{c}2.867 \\
(0.581)\end{array}$ \\
\hline
\end{tabular}

